\title{
SCIDOC
}

\author{
International Journal of Dentistry and Oral Science (IJDOS) \\ ISSN: 2377-8075
}

\section{Silver Diamine Fluoride in Reducing Dentin Hypersensitivity In Vital Tooth Preparation: A Case Report}

Case Report

Sami Aldhuwayhi ${ }^{1 *}$

${ }^{1}$ Head and Assistant Professor, Department of Prosthodontics, College of Dentistry, Majmaah University, Al-Zulfi, Riyadh Province, Kingdom of Saudi Arabia.

\section{Abstract}

Silver diamine fluoride (SDF) is a therapeutic agent which contains antibacterial and remineralizing effects. The SDF is extensively used in the management of dental caries in children and adults. SDF can be used to prevent dental caries, arrest the dental carious lesions, and potentially impact dentin hypersensitivity. Dentin hypersensitivity is one of the significant challenges in vital tooth preparations. It is imperative to manage the dentin hypersensitivity in those patients planned for vital tooth preparations. Therefore the purpose of the present case report was to describe the use of SDF in a patient who has undergone vital preparation to reduce dentin hypersensitivity.

Keywords: Silver Diamine Fluoride; Dentin Hypersensitivity; Vital Tooth; Tooth Preparation.

\section{Introduction}

Silver diamine fluoride (SDF) is a clear solution that has many advantages in dentistry. SDF is a liquid agent of a $\mathrm{pH}-10,24.4 \%$ to $28.8 \%$ of silver and 5.0 to $5.9 \%$ of fluoride [1]. Originally SDF has introduced a century ago in dentistry. There is sufficient evidence that reported SDF is a caries arrest and preventive agent. $\mathrm{SDF}$ application is a non-invasive technique that is very simple to use and quick in the process. It is a safe, painless alternative to traditional cavity drilling procedures [2]. Silver ions in SDF work as antimicrobial agents, while fluoride helps form fluorohydroxyapatite and ammonia, stabilizing the components in SDF solution [1, 3]. Application of SDF penetrates to hard tissues of the tooth and forms the 2 to 3 fluoride sub-surfaces on the tooth compared to other fluoride applications used in dentistry [2, 3]. SDF-applied tooth acts as a fluoride reservoir, and it increases the duration of effectiveness. SDF reacts with hydroxyapatite crystals and forms fluorapatite, avoiding further invasion of bacteria into the tooth structures [4]. SDF works as caries arresting and preventive agent and also a good desensitizing agent $[1,4]$.

Short-term pain ascending from the affected dentin in response to touch, cold, hot, chemical stimulus and it is also known as sen- sitive teeth is called as dentin hypersensitivity [5]. Dentinal hypersensitivity may be instigated by various reasons like professional oral hygiene, vital tooth preparations, dental bleaching, trauma, acidic beverages and foods, periodontal pathologies, and improper brushing techniques [6]. Dentin hypersensitivity disturbs daily habits such as drinking, eating, and sometimes breathing. It has been reported that the prevalence of dentin hypersensitivity was from $25 \%$ to $40 \%$ and more common in males[7].

Desensitizing agents are frequently used to reduce dentin hypersensitivity and especially in vital tooth preparations [8]. The desensitizing agents such as silver diamine fluoride, topical fluoride, lasers, and fluorides contain silver ions extensively used in dentistry. Densensitidsing agents to minimize dentin hypersensitivity could be home-based or dental operatory-based [9] (Figure 1). The SDF is also very extensively used for dentine hypersensitivity. Castillo et al. [10] reported that topical application of SDF efficiently minimizes teeth pain from one day to one week. The mechanism behind the use of SDF application in vital tooth preparation not been studied frequently. Hence the purpose of the present report was to explain the use of SDF in vital tooth preparations to reduce dentin hypersensitivity.

*Corresponding Author:

Dr. Sami Aldhuwayhi BDS(KSA), DClinDent (UK),

Head and Assistant Professor, Department of Prosthodontics, College of Dentistry, Majmaah University, Al-Zulfi, Riyadh Province, Kingdom of Saudi Arabia.11952. Tel: +966-50-6234530

E-mail: s.aladdowihi@mu.edu.sa

Received: April 01, 2021

Accepted: July 31, 2021

Published: September 03, 2021

Citation: Sami Aldhuwayhi. Silver Diamine Fluoride in Reducing Dentin Hypersensitivity In Vital Tooth Preparation: A Case Report. Int J Dentistry Oral Sci. 2021;8(9): 4187-4189. doi: 10.19070/2377-8075-21000873

Copyright: Dr. Sami Aldhuwayhi ${ }^{\circ} 2021$. This is an open-access article distributed under the terms of the Creative Commons Attribution License, which permits unrestricted use, distribution and reproduction in any medium, provided the original author and source are credited. 
Figure 1. The treatment options available for dentin hypersensitivity.

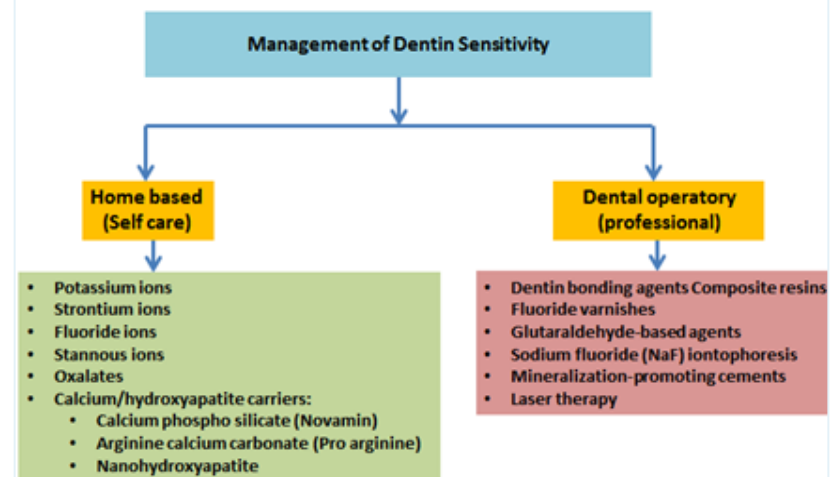

Figure 2. Intraoral clinical picture showing missing teeth.

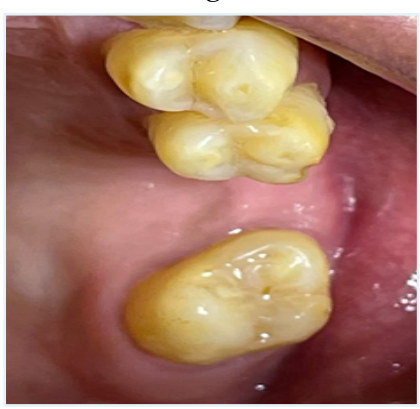

Figure 4. Intraoral clinical picture showing silver diamine fluoride applied prepared teeth 15 and 18.

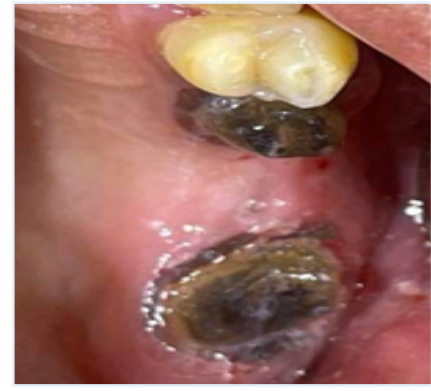

Figure 3. Use an micro brush applicator brush to apply silver diamine fluoride (Fagamin) on the tooth surface.

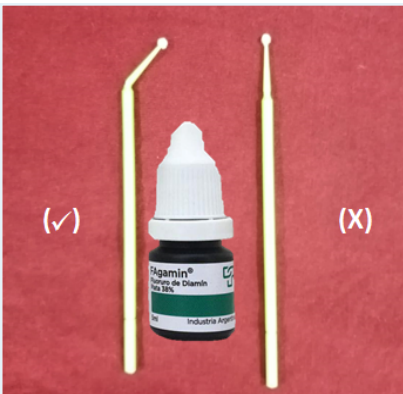

Figure 5. Intraoral clinical picture showing fixed prosthesis.

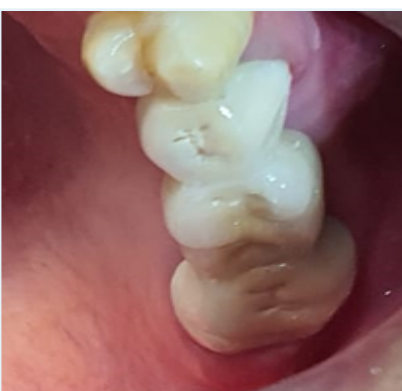

\section{Case Report}

A 38-year-old male attended a specialty consultation clinic for the replacement of missing teeth. His dental history revealed he had undergone multiple extractions due to carious lesions. He is a diabetic patient, and otherwise, his medical history is not remarkable. His oral hygiene was inadequate. The clinical and radiographic examination revealed multi-missing teeth in the maxillary arch. The treatment options include removable partial dentures, fixed partial dentures, and implant-supported dentures were advised. Upon discussion with the patient, it was decided to plan a fixed prosthesis. At the first visit, oral hygiene instructions were given. 16 and 17 were missing in the first quadrant teeth, and mesially tilted tooth 18 was observed (Figure.2). The fixed prosthesis was planned upon discussing with the multidisciplinary specialty clinic. Tooth 15 and tooth 18 were prepared under local anesthesia, considering and planned for fixed prosthesis. After cleaning the teeth with cotton rolls, protect face skin, gums, and cheeks with cotton rolls, and dry affected teeth; SDF (Fagamin Silver Diamine Fluoride $38 \% \mathrm{SDF}$ ) was directly applied with a bent applicator tip (Figure 3) onto the affected teeth surface for 3 minutes. The excess was removed with cotton or micro brush applicator tips and then rinsed with water. The protocol followed for the placement of SDF for vital tooth preparation was summurised in Table 1.
Since it is vital tooth to avoid dentin hypersensitivity, SDF was applied (Figure 4) followed by temporized acrylic crowns. Upon one follow visit fixed partial prosthesis was given (Figure 5).

\section{Discussion}

Various mechanisms had have been proposed for dentinal hypersensitivity in the published literature. These include Brannstrom's fluid hydrodynamic theory [11] and odontoblast receptors [12], and direct innervation theory [13]. These dentinal tubules consisting of dentinal fluids extend through the entire dentine thickness from pulp to dentinoenamel junction. Tooth preparation is the essential and foremost step in prosthetic rehabilitation. It is irreversible calculated removal of tooth structure to inculcate the structural durability of the prosthesis. One of the significant disadvantages of vital tooth preparation is dentinal hypersensitivity [14]. Dentinal hypersensitivity is the most common clinical condition arising from vital tooth preparation associated with exposed dentinal surfaces. Diminutive shooting pain originates from unprotected dentin in response to stimulus like tactile, thermal, chemical or osmotic that is not associated with dental defect or pathology $[7,8]$. Dentinal hypersensitivity is high in females than in males and affects any age group but most commonly affected patients age group of 20-50 years with the peak between $30-40$ 
Table 1. Recommended Protocol for application of Silver diamine fluoride in vital tooth preparations.

\begin{tabular}{|c|c|}
\hline Step & Procedure \\
\hline Step 1 & Local anesthesia administration \\
\hline Step 2 & Tooth preparation \\
\hline Step 3 & Tooth selection (vital Tooth) \\
\hline Step 4 & Isolation of selected tooth with any isolation methods \\
\hline Step 5 & Dry the tooth with cotton or tooth brush \\
\hline Step 6 & Dispense the Silver diamine fluoride liquid into dappen dish \\
\hline Step 7 & \multirow{2}{*}{$\begin{array}{l}\text { Application of Silver diamine fluoride } \\
\text { Bend the applicator tip (Figure 2) } \\
\text {. } \text { Dip the brush into silver diamine fluoride and dab onto the side of the plastic dappen dish to remove } \\
\text { excess liquid before application onto the teeth prepared. } \\
\text {. Apply silver diamine fluoride directly to the affected tooth surface only. } \\
\text {. Remove the excess SDF with gauze, cotton roll, or cotton pellet to minimize systemic absorption. } \\
\text { Wait till discoloration (3 minutes) }\end{array}$} \\
\hline Step 8 & \\
\hline Step 9 & Temporary crowns placement \\
\hline Step 10 & Fixed prosthesis \\
\hline
\end{tabular}

years [11].

Dentinal tubules are exposed during tooth preparation and cause hypersensitivity in [14]. This hypersensitivity can be treated by many desensitizing agents [9]. Among these, SDF is also an excellent agent that could give quick relief. The use of CO2 laser and SDF has also been reported to be very effective in minimizing dentin hypersensitivity in the case of vital tooth preparations [11]. SDF application is one best aid to reduce hypersensitivity in vital tooth preparation [15]. There is sufficient evidence to establish the SDF mechanism in blocking dentinal tubules [16-18]. Nonetheless, in vital tooth preparations, SDF can reduce dentin hypersensitivity by blocking the exposed dentinal tubules. It has been reported that dentin hypersensitivity is one of the most common problems encountered in patients with vital tooth preparations $[10,14,17]$. In the present case, SDF was applied to avoid dentin hypersensitivity at the same visit of crown preparation. This case serves as one of the best examples to explain the application of SDF on vital crown preparations.

\section{Conflict Of Interest}

The Auhtor have no conflicts of interests to declare.

\section{Acknowledgment}

The Author would like to thank the Deanship of Scientific Research at Majmaah University for supporting this work.

\section{Conclusion}

Silver diamine fluoride is the feasible agent to reduce dentin hypersensitivity in vital tooth preparations. The application SDF could be done at the same time as vital tooth preparations.

\section{References}

[1]. Punhagui MF, Jussiani EI, Andrello AC, Favaro JC, Guiraldo RD, Lopes $\mathrm{MB}$, Berger SB. Effect of application time and concentration of silver diamine fluoride on the enamel remineralization. J Clin Exp Dent. $2021 \mathrm{Jul}$ 1;13(7):e653-e658. Pubmed PMID: 34306528.

[2]. Sulyanto RM, Kang M, Srirangapatanam S, Berger M, Candamo F, Wang Y, Dickson JR, Ng MW, Ho SP. Biomineralization of Dental Tissues Treated with Silver Diamine Fluoride. J Dent Res. 2021 Sep;100(10):1099-1108. Pubmed PMID: 34323107.

[3]. Haiat A, Ngo HC, Samaranayake LP, Fakhruddin KS. The effect of the combined use of silver diamine fluoride and potassium iodide in disrupting the plaque biofilm microbiome and alleviating tooth discoloration: A systematic review. PLoS One. 2021 Jun 11;16(6):e0252734. Pubmed PMID: 34115788.

[4]. Seifo N, Cassie H, Radford JR, Innes NPT. Silver diamine fluoride for managing carious lesions: an umbrella review. BMC Oral Health. $2019 \mathrm{Jul}$ 12;19(1):145. Pubmed PMID: 31299955.

[5]. Holland GR, Narhi MN, Addy M, Gangarosa L, Orchardson R. Guidelines for the design and conduct of clinical trials on dentine hypersensitivity. J Clin Periodontol. 1997 Nov;24(11):808-13. Pubmed PMID: 9402502.

[6]. West NX, Lussi A, Seong J, Hellwig E. Dentin hypersensitivity: pain mechanisms and aetiology of exposed cervical dentin. Clin Oral Investig. 2013 Mar;17 Suppl 1:S9-19. Pubmed PMID: 23224116.

[7]. Rees JS, Jin LJ, Lam S, Kudanowska I, Vowles R. The prevalence of dentine hypersensitivity in a hospital clinic population in Hong Kong. J Dent. 2003 Sep;31(7):453-61. Pubmed PMID: 12927456.

[8]. Sgolastra F, Petrucci A, Gatto R, Monaco A. Effectiveness of laser in dentinal hypersensitivity treatment: a systematic review. J Endod. 2011 Mar;37(3):297-303. Pubmed PMID: 21329811.

[9]. van Loveren C, Schmidlin PR, Martens LC, Amaechi BT. Dentin hypersensitivity management. Clinical Dentistry Reviewed. 2018 Nov;2(1):6.

[10]. Castillo JL, Rivera S, Aparicio T, Lazo R, Aw TC, Mancl LL, Milgrom P. The short-term effects of diammine silver fluoride on tooth sensitivity: a randomized controlled trial. J Dent Res. 2011 Feb;90(2):203-8. Pubmed PMID: 21118796.

[11]. BRAENNSTROEM M, ASTROEM A. A STUDY ON THE MECHANISM OF PAIN ELICITED FROM THE DENTIN. J Dent Res. 1964 Jul-Aug;43:619-25. Pubmed PMID: 14183350.

[12]. Rapp R, Avery JK, Strachan DS. Possible role of the acetylcholinesterase in neural conduction within the dental pulp. University of Alabama Press, Birmingham; 1968.309-31.

[13]. Irvine JH. Root surface sensitivity: a review of aetiology and management. J N Z Soc Periodontol. 1988 Nov;(66):15-8. Pubmed PMID: 3078601.

[14]. Yadav K, Sofat A, Gambhir RS, Galhotra V. Dentin hypersensitivity following tooth preparation: A clinical study in the spectrum of gender. J Nat Sci Biol Med. 2014 Jan;5(1):21-4. Pubmed PMID: 24678191.

[15]. Aldhuwayhi S, Shaikh SA, Thakare AA, Mustafa MZ, Mallineni SK. Remote Management of Prosthodontic Emergencies in the Geriatric Population During the Pandemic Outbreak of COVID-19. Front Med (Lausanne). 2021 Jul 28;8:648675. Pubmed PMID: 34395459.

[16]. Nuvvula S, Mallineni SK. Silver Diamine Fluoride in Pediatric Dentistry. Journal of South Asian Association of Pediatric Dentistry. 2019 Jul;2(2):74.

[17]. Contreras V, Toro MJ, Elías-Boneta AR, Encarnación-Burgos A. Effectiveness of silver diamine fluoride in caries prevention and arrest: a systematic literature review. Gen Dent. 2017 May-Jun;65(3):22-29. Pubmed PMID: 28475081.

[18]. Crystal YO, Niederman R. Evidence-Based Dentistry Update on Silver Diamine Fluoride. Dent Clin North Am. 2019 Jan;63(1):45-68. Pubmed PMID: 30447792. 